\title{
EXPERIMENTAL STUDY AND CALCULATION OF CONFINEMENT RELATIONSHIPS FOR PRESTRESSED STEEL TUBE-CONFINED COMPRESSED CONCRETE STUB COLUMNS
}

\author{
Mahdi NEMATZADEH ${ }^{\mathrm{a}}$, Morteza NAGHIPOUR ${ }^{\mathrm{b}}$, Javad JALALI ${ }^{\mathrm{b}}$, Abolghasem SALARI ${ }^{\mathrm{b}}$ \\ ${ }^{a}$ Department of Civil Engineering, University of Mazandaran, 47416-13534, Babolsar, Iran \\ ${ }^{b}$ Faculty of Civil Engineering, Babol University of Technology, 47148-71167, Babol, Iran
}

Received 04 May 2016; accepted 18 Aug 2016

\begin{abstract}
The current paper aims to present the results of an experimental investigation into the compressive strength of prestressed steel tube-confined compressed concrete (PSTC) stub columns. Here, to prestress the confined concrete, an innovative technique is utilized, in which the fresh concrete is subjected to compression while the steel tube is simultaneously pretensioned laterally by applying external pressure to the fresh concrete. A total of 135 confined specimens were tested under axial compressive loading to determine the confinement strength of the specimens. Moreover, new confinement relationships for the load-carrying capacity of the PSTC columns were proposed in terms of the prestressing ratio $\left(P_{r}\right)$, reference concrete strength $\left(f_{c}\right)$, and tube outer diameter to wall thickness ratio $(D / t)$. Finally, a parametric study was conducted to evaluate the effect that the parameters $P_{r}, f_{c}$, and $D / t$ have on the compressive strength of the prestressed confined concrete. The results indicate that the confined concrete prestressed by the present technique demonstrates significantly enhanced load-carrying capacity; however, increasing the prestressing level slightly affects it.
\end{abstract}

Keywords: active confinement, steel tube, compressed concrete, prestressing, confinement relationships, load-carrying capacity, STCC.

\section{Introduction}

Concrete-filled steel tube (CFST) columns have been widely used in many engineering structures in that the CFST columns combine the best characteristics of both steel and concrete materials including high strength, high ductility, and high stiffness (Dundu 2012). In a CFST column, the steel tube and the concrete core are loaded simultaneously; however, the steel tube in these columns will be less effective in confining the concrete in comparison with the steel tube-confined concrete (STCC) columns in which only the concrete core is loaded (Yu et al. 2010). Hence, the STCC columns provide greater strength and ductility as well as the lower chance of steel tube buckling compared to the CFST columns (Yu et al. 2010). STCC columns were first investigated by Tomii et al. $(1985,1987)$, and since then, several research results on the STCC columns have been reported by different researchers in the literature (Han et al. 2005, 2009; Zhang et al. 2013; Xiao 2005; Dong, Ho 2015; Lee et al. 2014).

In the STCC columns with passive confinement, the steel tube has no initial lateral stress, therefore, for an effective confinement, a large deformation of the concrete core in the lateral direction and consequently in the axial direction is required. This fact increases micro-crack formation in the concrete. For this reason, in many codes of practice, the strength improvement due to the confinement is either neglected (ACI 318M-08:2008; AS3600:1994; CSA A23.3-04:2004) or insignificantly considered (EC4 part1-1:2004; ANSI/AISC 360-05:2005; CAN/CSA S1601:2001). One way to prevent large deformations of concrete and the subsequent damage is to apply an initial lateral pressure to the concrete core by prestressing the steel tube, known as "active confinement", as opposed to "passive confinement". Applying active confinement to the concrete leads to an improvement in its compressive behavior in terms of strength and ductility. Currently, there are various methods for prestressing the confining devices (Feeser, Chinn 1962; Martin 1968; KrstulovicOpara, Thiedeman 2000; Mortazavi et al. 2003; Mokari, Moghadam 2008; Shinohara 2008; Chang et al. 2009; Janke et al. 2009; Moghaddam et al. 2010; Tran et al. 2015).

During the 1960s, Feeser and Chinn (1962), as well as Martin (1968), carried out experiments on concrete cylinders, which were laterally prestressed using thin continuous wires. Their results showed that prestress-

Corresponding author: Mahdi Nematzadeh

E-mail:m.nematzadeh@umz.ac.ir 
ing the wires at very low levels of confining pressure extended the elastic range while negligibly affecting the axial capacity. However, the findings of Gardner et al. (1992) suggested that prestressing the confining wires can significantly increase the load-carrying capacity. Janke et al. (2009) in an experimental study conducted on the prestressed external confinement in the concrete compressive members confirmed the beneficial influence that prestressing the confinement had on the concrete residual capacity. The mechanical behavior of prestressed circular CFST columns made of expansive cement was studied in the work of Chang et al. (2009), and the improvement of load-carrying capacity due to pre-tensioning the confining member was revealed.

This study proposes an innovative technique in order to create active confinement in the STCC columns, in which the steel tube prestressing and the concrete compressing are both carried out simultaneously by applying pressure on the fresh concrete. This technique was first proposed by Nemati (2006), subsequently employed and investigated by Nematzadeh (2012). Although the further investigation and experimental work are necessary to employ this technique in practical engineering applications, the performance of prestressed STCC columns produced on a small scale using a laboratory method, which was first conducted in this research, is a prerequisite for achieving this goal. In this research, the load-carrying capacity of prestressed steel tube-confined compressed concrete (PSTC) stub columns is experimentally investigated under axial compressive loading, and the results are compared with those of the normal STCC ones. Subsequently, confinement equations are proposed for the active and passive STCC specimens and are compared with those reported by others in the literature. A parametric study is also performed to assess the effects of prestressing ratio $\left(P_{r}\right)$, reference concrete strength $\left(f_{c}\right)$, and outer diameter to wall thickness ratio of the steel tube $(D / t)$ on the compressive strength of the PSTC specimens. The results of this research indicate that the confined concrete prestressed by the present technique demonstrates significantly improved load-carrying capacity.

\section{Experimental program}

\subsection{Test specimens}

For this study, 15 groups of specimens with different values of $P_{r}, f_{c}$ and $D / t$ were tested. Eighteen test specimens were produced for each group, which were divided into six categories each containing three specimens (in triplicate), namely long-term prestressed steel tube-confined compressed concrete (LPSTC), short-term prestressed steel tube-confined compressed concrete (SPSTC), non-prestressed steel tube-confined concrete (NPSTC), reference concrete (RC), long-term pressurecompressed concrete (LPCC), and short-term pressurecompressed concrete (SPCC). The LPCC and SPCC specimens represent the unconfined compressed concrete ones and serve as the concrete core of the LPSTC and
SPSTC, respectively. The compressive strength of these concrete specimens is obtained by using the equations proposed in the previous article (Nematzadeh, Naghipour 2012a) in terms of the compressive strength of reference concrete (RC). According to the above definitions, the LPSTC and SPSTC have an active confinement while the NPSTC has a passive one. In addition, the longterm pressure applied to the fresh concrete lasts for up to 6 days while the short-term pressure in the prestressed specimens lasts only 15-30 min during which a stable pressure must be established. The compressed concrete specimens are removed from their tubes in order to separately assessing the contributions that compressing the fresh concrete, prestressing the steel tube, and confining the concrete core have on the improvement of the loadbearing capacity. The detailed information on all the confined specimens is given in Table 1.

In the notation system chosen for identifying the specimens, the first letter represents the type of the confined concrete (with L, S, and N representing the LPSTC, SPSTC, and NPSTC specimens, respectively), and the first number denotes the design compressive strength of the associated unconfined concrete in $\mathrm{MPa}$. The letter $\mathrm{P}$ along with the second number demonstrate the initial lateral pressure applied to the fresh concrete, expressed in terms of the circumferential strain of the steel tube in microstrain; however, for the passively-confined concrete specimens having no initial pressure, this notation is used only to distinguish them from other similar specimens. Also, the third number specifies the wall thickness of the steel tube in $\mathrm{mm}$.

\subsection{Materials}

The design compressive strength of the uncompressed concrete in seven different batches was selected ranging from 15 to $55 \mathrm{MPa}$, according to the concrete mix design recommended by the ACI 211 (ACI Committee 211.191:2000). In all the concrete mixtures, the crushed stone with a maximum size of $12.5 \mathrm{~mm}$ was utilized as coarse aggregate, and also the fluvial sand and Type I Portland cement were used as well. Moreover, no additive was used in the concrete mixes.

Steel tubes used in this research were of a hot-rolled and seamless type. The steel tubes were all of the same type and had the length and internal diameter of 150 and $55.5 \mathrm{~mm}$, respectively, with four different values for the steel tube thickness, i.e. 1.0, 1.5, 2.0, and $2.5 \mathrm{~mm}$. To obtain different values for the steel tube thickness, the outer surface of the tubes was shaved by a metal lathe while the inner diameter of the steel tubes remained constant. The mechanical properties of the steel tube were determined using the standard test ASTM A370 (2003), and the obtained results are given in Table 2 .

\subsection{Instrumentation and test setup}

Prestressing the confined concrete was performed in a pressure apparatus manufactured by the authors; full de- 
Table 1. Specimen information

\begin{tabular}{|c|c|c|c|c|}
\hline $\begin{array}{l}\text { Specimen } \\
\text { identifier }\end{array}$ & $L \times D \times t(\mathrm{~mm})$ & $\begin{array}{c}\text { Initial circumferential strain of } \\
\text { steel tube in } \mu \text { s (Initial lateral } \\
\text { pressure in } \mathrm{MPa} \text { ) }\end{array}$ & $\begin{array}{c}\text { Final circumferential strain of } \\
\text { steel tube in } \mu \text { s (Final lateral } \\
\text { pressure in } \mathrm{MPa} \text { ) }\end{array}$ & $\begin{array}{l}\text { Total pressure } \\
\text { loss ratio }(\%)\end{array}$ \\
\hline L25P350-2.5 & $150 \times 60.5 \times 2.5$ & $367.2(6.9)$ & $233.3(4.4)$ & 36.5 \\
\hline $\mathrm{S} 25 \mathrm{P} 350-2.5$ & $150 \times 60.5 \times 2.5$ & $367.2(6.9)$ & $98.4(1.9)$ & 73.2 \\
\hline $\mathrm{N} 25 \mathrm{P} 350-2.5$ & $150 \times 60.5 \times 2.5$ & & & \\
\hline L25P950-1.5 & $150 \times 58.5 \times 1.5$ & $1006.6(11.4)$ & $729.4(8.3)$ & 27.5 \\
\hline $\mathrm{S} 25 \mathrm{P} 950-1.5$ & $150 \times 58.5 \times 1.5$ & $1006.6(11.4)$ & $179.0(2.0)$ & 82.2 \\
\hline N25P950-1.5 & $150 \times 58.5 \times 1.5$ & & & \\
\hline L25P650-1.5 & $150 \times 58.5 \times 1.5$ & $628.0(7.1)$ & $399.7(4.5)$ & 36.4 \\
\hline S25P650-1.5 & $150 \times 58.5 \times 1.5$ & $628.0(7.1)$ & $100.7(1.1)$ & 84 \\
\hline N25P650-1.5 & $150 \times 58.5 \times 1.5$ & & & \\
\hline L35P650-1.5 & $150 \times 58.5 \times 1.5$ & $658.0(7.5)$ & $400.5(4.5)$ & 39.1 \\
\hline S35P650-1.5 & $150 \times 58.5 \times 1.5$ & $658.0(7.5)$ & $119.5(1.4)$ & 81.8 \\
\hline N35P650-1.5 & $150 \times 58.5 \times 1.5$ & & & \\
\hline L15P650-1.5 & $150 \times 58.5 \times 1.5$ & $658.0(7.5)$ & $400.5(4.5)$ & 39.1 \\
\hline $\mathrm{S} 15 \mathrm{P} 650-1.5$ & $150 \times 58.5 \times 1.5$ & $658.0(7.5)$ & $119.5(1.4)$ & 81.8 \\
\hline N15P650-1.5 & $150 \times 58.5 \times 1.5$ & & & \\
\hline L25P950-2.5 & $150 \times 60.5 \times 2.5$ & $964.0(18.2)$ & $596.0(11.3)$ & 38.2 \\
\hline $\mathrm{S} 25 \mathrm{P} 950-2.5$ & $150 \times 60.5 \times 2.5$ & $964.0(18.2)$ & $168.7(3.2)$ & 82.5 \\
\hline N25P950-2.5 & $150 \times 60.5 \times 2.5$ & & & \\
\hline L50P650-2.5 & $150 \times 60.5 \times 2.5$ & $629.7(11.9)$ & $321.8(6.1)$ & 48.9 \\
\hline S50P650-2.5 & $150 \times 60.5 \times 2.5$ & $629.7(11.9)$ & $115.3(2.2)$ & 81.7 \\
\hline N50P650-2.5 & $150 \times 60.5 \times 2.5$ & & & \\
\hline L15P550-2.5 & $150 \times 60.5 \times 2.5$ & $543.5(10.3)$ & $267.8(5.1)$ & 50.7 \\
\hline $\mathrm{S} 15 \mathrm{P} 550-2.5$ & $150 \times 60.5 \times 2.5$ & $543.5(10.3)$ & $109.3(2.1)$ & 79.9 \\
\hline N15P550-2.5 & $150 \times 60.5 \times 2.5$ & & & \\
\hline L35P550-2.5 & $150 \times 60.5 \times 2.5$ & $543.5(10.3)$ & $267.8(5.1)$ & 50.7 \\
\hline S35P550-2.5 & $150 \times 60.5 \times 2.5$ & $543.5(10.3)$ & $109.3(2.1)$ & 79.9 \\
\hline N35P550-2.5 & $150 \times 60.5 \times 2.5$ & & & \\
\hline L25P500-2.5 & $150 \times 60.5 \times 2.5$ & $483.9(9.2)$ & $268.9(5.1)$ & 44.4 \\
\hline $\mathrm{S} 25 \mathrm{P} 500-2.5$ & $150 \times 60.5 \times 2.5$ & $483.9(9.2)$ & $64.5(1.2)$ & 86.7 \\
\hline N25P500-2.5 & $150 \times 60.5 \times 2.5$ & & & \\
\hline L25P650-2.0 & $150 \times 59.5 \times 2.0$ & $604.9(9.2)$ & $336.2(5.1)$ & 44.4 \\
\hline $\mathrm{S} 25 \mathrm{P} 650-2.0$ & $150 \times 59.5 \times 2.0$ & $604.9(9.2)$ & $80.6(1.2)$ & 86.7 \\
\hline N25P650-2.0 & $150 \times 59.5 \times 2.0$ & & & \\
\hline L45P650-1.5 & $150 \times 58.5 \times 1.5$ & $597.0(6.8)$ & $343.0(3.9)$ & 42.5 \\
\hline $\mathrm{S} 45 \mathrm{P} 650-1.5$ & $150 \times 58.5 \times 1.5$ & $597.0(6.8)$ & $203.3(2.3)$ & 65.9 \\
\hline N45P650-1.5 & $150 \times 58.5 \times 1.5$ & & & \\
\hline L25P2000-1.0 & $150 \times 57.5 \times 1.0$ & $1614.3(12.2)$ & $1159.0(8.8)$ & 46.1 \\
\hline $\mathrm{S} 25 \mathrm{P} 2000-1.0$ & $150 \times 57.5 \times 1.0$ & $1614.3(12.2)$ & $420.3(3.2)$ & 80.5 \\
\hline N25P2000-1.0 & $150 \times 57.5 \times 1.0$ & & & \\
\hline L47P650-1.5 & $150 \times 58.5 \times 1.5$ & $607.6(6.9)$ & $315.2(3.6)$ & 48.1 \\
\hline S47P650-1.5 & $150 \times 58.5 \times 1.5$ & $607.6(6.9)$ & $90.5(1.0)$ & 85.1 \\
\hline N47P650-1.5 & $150 \times 58.5 \times 1.5$ & & & \\
\hline L55P650-2.5 & $150 \times 60.5 \times 2.5$ & $689.2(13.0)$ & $346.0(6.5)$ & 49.8 \\
\hline S55P650-2.5 & $150 \times 60.5 \times 2.5$ & $689.2(13.0)$ & $51.0(1.0)$ & 92.6 \\
\hline N55P650-2.5 & $150 \times 60.5 \times 2.5$ & & & \\
\hline
\end{tabular}


Table 2. Mechanical properties of steel tube

\begin{tabular}{cccccc}
\hline $\begin{array}{c}\text { Yield strength } \\
(\mathrm{MPa})\end{array}$ & $\begin{array}{c}\text { Ultimate } \\
\text { strength (MPa) }\end{array}$ & $\begin{array}{c}\text { Modulus of } \\
\text { elasticity (GPa) }\end{array}$ & $\begin{array}{c}\text { Poissons' } \\
\text { ratio }\end{array}$ & $\begin{array}{c}\text { Strain hardening } \\
\text { modulus (GPa) }\end{array}$ & $\begin{array}{c}\text { Ultimate } \\
\text { strain (\%) }\end{array}$ \\
\hline 339 & 480 & 210 & 0.28 & 4.75 & 11.44 \\
\hline
\end{tabular}

tails of which are given in the previous papers (Nematzadeh, Naghipour 2012a, 2012b). This apparatus can be employed to achieve a given prestressing level for the successive specimens equally by applying pressure to the fresh concrete for a specified period of time. A general view of the apparatus is shown in Figure 1.

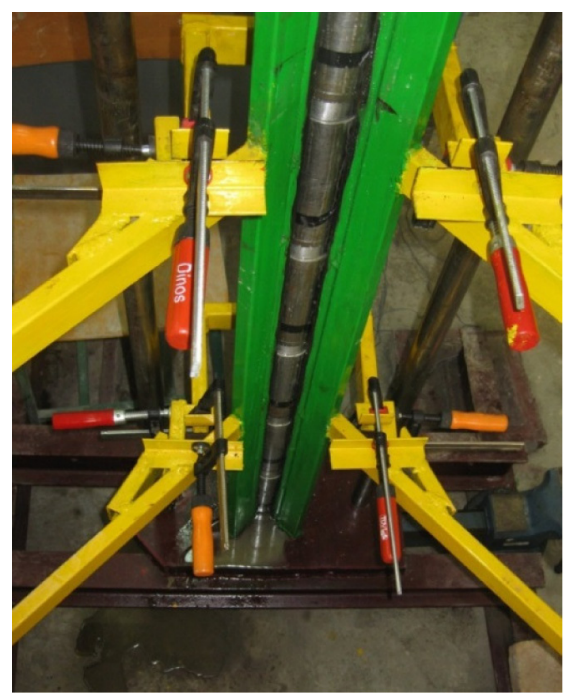

Fig. 1. General view of the pressure apparatus

The values of the initial and final pressure, and the pressure loss during a 28-day period for the prestressed specimens were measured by installing the strain gauges on the exterior surface of the steel tubes at the mid-height.

The tests were carried out using a $2000 \mathrm{kN}$ capacity ELE testing machine after a minimum 28-day curing time from the date of concreting. The load was increased based on a load-controlled strategy until the specimen failure occurred. The axial load was increased monotonically with an average load rate of $42 \mathrm{kN} / \mathrm{min}$ equivalent to $0.29 \mathrm{MPa} / \mathrm{s}$ which falls within the range of $0.15-0.35 \mathrm{MPa} / \mathrm{s}$ complying with the ASTM C39 (ASTM C39/C39M 2003) recommendations for concrete specimens. The end constraint effects of the loading platens on the compressive strength results of the confined concrete specimens are neglected. A schematic view of the loading conditions for the experimental STCC specimens together with a view of STCC columns in a concrete frame are shown in Figure 2.

\section{Test results and discussion}

\subsection{Prestressing loss}

The initial prestressing level (initial lateral confining pressure) of the prestressed confined concrete is gradually lost (a)

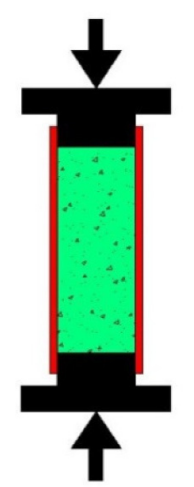

(b)

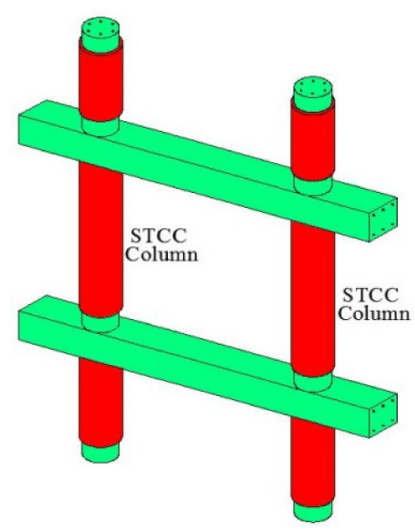

Fig. 2. A schematic view of: (a) loading conditions of the experimental STCC specimens (b) STCC columns in a structural concrete frame

during hardening of the concrete, which may be attributed to the shrinkage and creep of the compressed concrete. The initial prestressing level on the first day and the final prestressing after 28 days, as well as the total prestressing loss ratio, are listed in Table 1. The average values obtained for the total prestressing loss ratio $\left(\left(P_{i}-P_{f}\right) / P_{i}\right)$ are $42 \%$ and $81 \%$ for the LPSTC and SPSTC specimens, respectively. The final prestressing level which is required for evaluating the compressive strength of the activelyconfined concrete can be predicted in terms of the initial prestressing as follows:

$$
\begin{aligned}
& P_{f}=0.19 P_{i} \text { for SPSTC; } \\
& P_{f}=0.58 P_{i} \text { for LPSTC, }
\end{aligned}
$$

where $P_{i}$ and $P_{f}$ are the initial and final prestressing levels, respectively.

It can be found from Eqns (1) and (2) that the prestressing value of the LPSTC is about 3 times higher than that of SPCTC. The variation of the circumferential strain of steel tube (prestressing level) with respect to time is graphically illustrated in Figure 3.

\subsection{Compressive strength of confined concrete}

The most commonly used relationships for predicting the compressive strength of confined concrete are the equations developed by Richart et al. (1928) and Mander et al. (1988), which are written in the form of Eqns (3) and (4), respectively:

$$
\frac{f_{c c}-f_{c}}{f_{c}}=4.1 \frac{f_{l}}{f_{c}}
$$




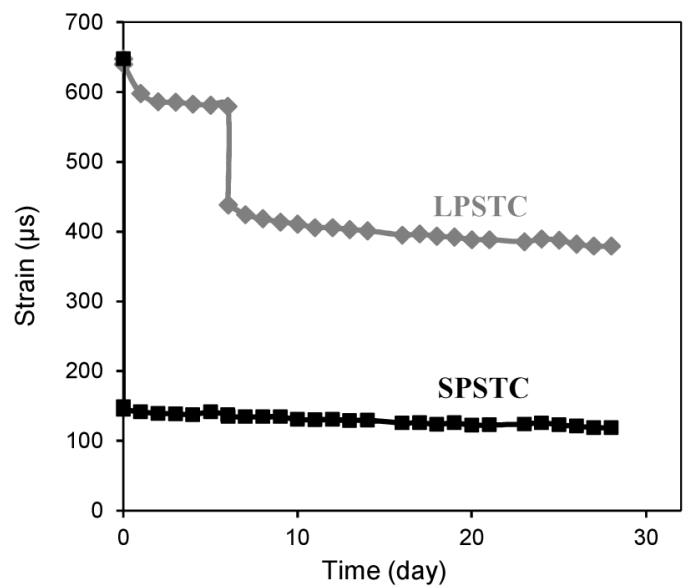

Fig. 3. Relationship of circumferential strain of steel tube (prestressing level) versus time

$$
\frac{f_{c c}-f_{c}}{f_{c}}=2.254 \sqrt{1+7.94 \frac{f_{l}}{f_{c}}}-2 \frac{f_{l}}{f_{c}}-2.254
$$

where $f_{c c}$ and $f_{c}$ are the compressive strength of confined and unconfined concrete, respectively, $f_{l}$ is the lateral confining pressure applied to the concrete core, and $f_{l} / f_{c}$ is referred to as confinement ratio $\left(C_{r}\right)$.

\subsubsection{Passively-confined concrete}

The compressive strength of the passively-confined concrete specimens is given in Table 3 . The relative increase in the compressive strength of the confined concrete compared with the corresponding unconfined concrete is presented in Table 3.

The confining pressure applied to the concrete core of passively-confined specimens corresponding to the compressive strength is determined based on the following equation which can generally be used for specimens confined with thin-walled circular tubes:

$$
f_{l}=\frac{2 t f_{y}}{D-2 t},
$$

where $D$ and $t$ are the outer diameter and wall thickness of the steel tube, respectively, and $f_{v}$ is the yield stress of steel. It should be noted that this equation is used for the confined concrete when the longitudinal stress of the steel tube is zero. Given the presence of a shear stress at the interface between the steel tube and concrete core due to the friction between the two, a compressive longitudinal stress is produced in the steel tube of the NPSTC specimens. According to von-Mises yield criteria, circumferential stress of the steel tube $\left(\sigma_{\theta}\right)$ can be calculated in terms of its longitudinal to circumferential stress ratio $(\alpha)$ as follows:

$$
\sigma_{\theta}=\frac{f_{y}}{\sqrt{1+\alpha+\alpha^{2}}}
$$

The longitudinal to circumferential stress ratio can be obtained by using the elastic-plastic theory and having

\begin{tabular}{|c|c|c|c|c|c|c|c|c|c|c|}
\hline 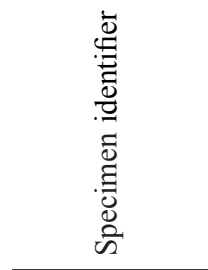 & 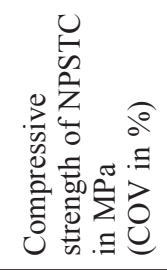 & 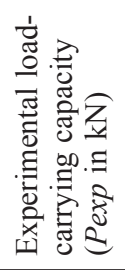 & 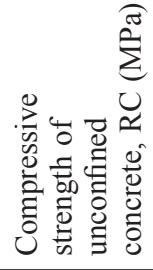 & 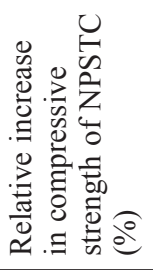 & 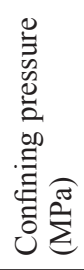 & 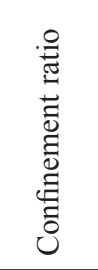 & 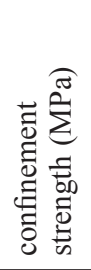 & 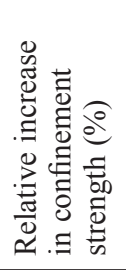 & 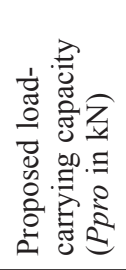 & $\begin{array}{l}3 \\
\frac{3}{2} \\
\frac{2}{2} \\
\vdots \\
2\end{array}$ \\
\hline $\mathrm{N} 25 \mathrm{P} 350-2.5$ & $111.6(1.7)$ & 270.0 & 28.2 & 295.7 & 17.6 & 0.625 & 74.7 & 165.1 & 250.5 & 0.93 \\
\hline N25P950-1.5 & $74.8(1.3)$ & 181.0 & 31.7 & 136.0 & 10.6 & 0.333 & 53.1 & 67.4 & 185.1 & 1.02 \\
\hline N25P650-1.5 & $75.0(3.0)$ & 181.4 & 28.3 & 165.0 & 10.6 & 0.374 & 53.3 & 88.2 & 176.9 & 0.98 \\
\hline N35P650-1.5 & $83.3(1.6)$ & 201.5 & 42.4 & 96.5 & 10.6 & 0.249 & 61.6 & 45.2 & 211.0 & 1.05 \\
\hline N15P650-1.5 & $63.7(1.5)$ & 154.1 & 20.5 & 210.7 & 10.6 & 0.516 & 42.0 & 104.7 & 158.0 & 1.03 \\
\hline N25P950-2.5 & $99.3(3.9)$ & 240.2 & 30.0 & 231.0 & 17.6 & 0.587 & 62.4 & 108.2 & 254.9 & 1.06 \\
\hline N50P650-2.5 & $132.7(1.2)$ & 321.0 & 50.5 & 162.8 & 17.6 & 0.349 & 95.8 & 89.8 & 304.5 & 0.95 \\
\hline N15P550-2.5 & $90.3(6.9)$ & 218.5 & 16.7 & 440.7 & 17.6 & 1.054 & 53.4 & 220.0 & 222.7 & 1.02 \\
\hline N35P550-2.5 & $113.0(1.9)$ & 273.4 & 37.1 & 204.6 & 17.6 & 0.475 & 76.1 & 105.2 & 272.0 & 1.00 \\
\hline $\mathrm{N} 25 \mathrm{P} 500-2.5$ & $99.5(1.2)$ & 240.7 & 27.2 & 265.8 & 17.6 & 0.647 & 62.6 & 130.3 & 248.1 & 1.03 \\
\hline $\mathrm{N} 25 \mathrm{P} 650-2.0$ & $83.6(2.2)$ & 202.2 & 27.2 & 207.4 & 14.1 & 0.518 & 54.4 & 99.9 & 211.0 & 1.04 \\
\hline N45P650-1.5 & $99.7(3.1)$ & 241.2 & 45.4 & 119.6 & 10.6 & 0.233 & 78.0 & 71.7 & 218.3 & 0.90 \\
\hline N25P2000-1.0 & $58.1(5.1)$ & 140.6 & 25.9 & 124.3 & 7.0 & 0.272 & 43.7 & 68.9 & 134.6 & 0.96 \\
\hline N47P650-1.5 & $101.1(0.6)$ & 244.6 & 46.9 & 115.6 & 10.6 & 0.225 & 79.4 & 69.2 & 221.9 & 0.91 \\
\hline N55P650-2.5 & $132.1(3.1)$ & 319.6 & 52.6 & 151.1 & 17.6 & 0.335 & 95.2 & 81.1 & 309.5 & 0.97 \\
\hline
\end{tabular}
the longitudinal and circumferential strain of steel tubes.

Table 3. Results of passively-confined concrete 
The confining pressure at the compressive strength of the NPSTC specimens in a biaxial stress condition for the steel tube is determined by substituting $f_{y}$ from Eqn (6) for that in Eqn (5), which gives:

$$
f_{l}=\frac{2 t f_{y}}{(D-2 t) \sqrt{1+\alpha+\alpha^{2}}} .
$$

The experimental results of this study indicate that the longitudinal to circumferential stress ratio of the steel tube at mid-height for the NPSTC specimen is about 1. Hence, $f_{l}$ and $C_{r}$ at the compressive strength of the NPSTC are calculated by Eqn (8):

$$
f_{l}=\frac{2 t f_{y}}{\sqrt{3}(D-2 t)} ; \quad C_{r}=\frac{2 t f_{y}}{\sqrt{3}(D-2 t) f_{c}} .
$$

To obtain the confinement relationships of the axial load-carrying capacity for the passively-confined concrete, only the circumferential strength contribution of the steel tube which is related to the confining pressure should be considered. This is done by subtracting the longitudinal strength contribution of the steel tube from the total compressive strength of the confined concrete, which is defined in this study as the "confinement strength". The confinement strength of the NPSTC specimens and its increase relative to the compressive strength of the corresponding unconfined concrete are given in Table 3.

The relationship between the relative increase in the confinement strength of the NPSTC and the confinement ratio is illustrated in Figure 4. As shown, the relative increase in the confinement strength is improved as $C_{r}$ increases. Using the regression analysis based on the least squares method, a linear equation is proposed to predict the relative increase in the confinement strength in terms of the confinement ratio, written as follows:

$$
\frac{f_{p c}-f_{c}}{f_{c}}=2.17 \frac{f_{l}}{f_{c}} ; \quad R^{2}=0.89
$$

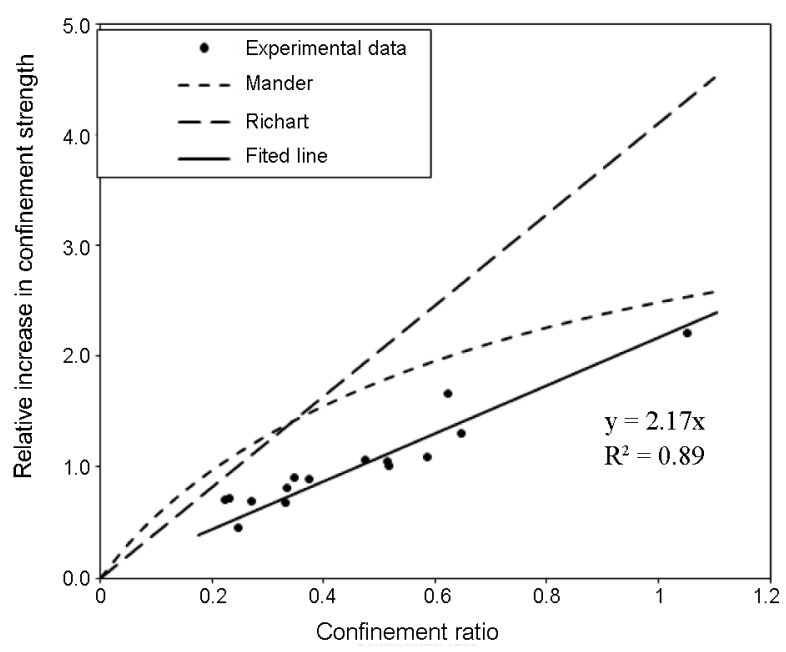

Fig. 4. Relationship of relative increase in confinement strength of NPCFT versus confinement ratio where $f_{p c}$ is the confinement strength of the passivelyconfined concrete defined as the ratio of the load-carrying capacity lacking the longitudinal strength contribution of the steel tube to the concrete cross-sectional area of the NPSTC. For comparison, the confinement relationships developed by Richart and Mander are also added to Figure 4. Due to experiencing biaxial stress by the steel tube in the NPSTC, a reduction in the effective confinement occurs. Note that Richart and Mander's confinement relationships were experimentally obtained for the concrete confined with the hydraulic pressure of the fluid and stirrup, respectively; in both of which there is no shear stress at the interface between the confining means and the concrete core.

The ratio of the relative increase in the confinement strength to the confinement ratio is known as the "confinement effectiveness coefficient" $(k)$. The results of this research indicate that the confinement effectiveness coefficient of the NPSTC is almost constant and equal to 2.17 , which is about half the value in Richart's relationship $(k=4.1)$. Also, the confinement effectiveness coefficient in Mander's relationship varies between 2.4 and 4.7, which is nearly 1 to 2 times greater than that of the present relationship.

The total load-carrying capacity of the NPSTC can normally be obtained through combining the strength values of the composite components as follows:

$$
P_{p c}=A_{s} f_{y} \frac{\alpha}{\sqrt{1+\alpha+\alpha^{2}}}+A_{c}\left(f_{c}+k \frac{2 t f_{y}}{(D-2 t) \sqrt{1+\alpha+\alpha^{2}}}\right) .
$$

In this study, $k$ and $\alpha$ were equal to 2.17 and 1 , respectively. Therefore, the load-carrying capacity of the NPSTC takes the following form:

$$
P_{p c}=0.58 A_{s} f_{y}+\left(1+2.51 \frac{t f_{y}}{(D-2 t) f_{c}}\right) A_{c} f_{c} .
$$

The results obtained from the proposed model as well as their ratios to those of the experiments are listed in Table 3, in which as can be seen, these ratios are in the range of 0.90 and 1.06 , indicating the reasonable accuracy of the proposed model. The experimental, as well as the proposed load-carrying capacity of the NPSTC specimens, are also shown in Figure 5.

\subsubsection{Actively-confined concrete}

The test results of the actively-confined compressed concrete are shown in Table 4, where the ratio of the compressive strength of the actively-confined concrete to that of the passively-confined one is given as ranging from 1.5 to 2 for the LPSTC and from 1.4 to 1.9 for the SPSTC. These results suggest that changing the confinement type to active one can significantly increase the load-carrying capacity of the confined concrete. 
Table 4. Compressive strength results of actively-confined concrete

\begin{tabular}{|c|c|c|c|c|c|c|c|}
\hline $\begin{array}{l}\text { Specimen } \\
\text { identifier }\end{array}$ & $\begin{array}{l}\text { Compressive } \\
\text { strength of } \\
\text { PSTC in } \\
\mathrm{MPa}(\mathrm{COV} \\
\text { in } \%)\end{array}$ & $\begin{array}{l}\text { Experimental } \\
\text { load-carrying } \\
\text { capacity } \\
(\text { Pexp in } \mathrm{kN})\end{array}$ & $\begin{array}{l}\text { Ratio of } \\
\text { compressive } \\
\text { strength of } \\
\text { PSTC to } \\
\text { NPSTC }\end{array}$ & $\begin{array}{l}\text { Relative } \\
\text { increase in } \\
\text { compressive } \\
\text { strength } \\
\text { of LPSTC } \\
\text { compared with } \\
\text { SPSTC }(\%) \\
\end{array}$ & $\begin{array}{l}\text { Compressive } \\
\text { strength of } \\
\text { LPCC and } \\
\text { SPCC }(\mathrm{MPa})\end{array}$ & $\begin{array}{c}\text { Portion of } \\
\text { compressing } \\
\text { concrete } \\
\text { in relative } \\
\text { increase } \\
\text { of PSTC } \\
\text { strength }(\%) \\
\end{array}$ & $\begin{array}{l}\text { Relative increase } \\
\text { in compressive } \\
\text { strength of } \\
\text { PSTC compared } \\
\text { with compressed } \\
\text { concrete }(\%)\end{array}$ \\
\hline L25P350-2.5 & $166.8(2.0)$ & 403.5 & 1.49 & 2 & 63.5 & 1.3 & 162.7 \\
\hline $\mathrm{S} 25 \mathrm{P} 350-2.5$ & $163.5(3.0)$ & 395.5 & 1.47 & & 61.3 & & 166.7 \\
\hline L25P950-1.5 & $134.9(1.3)$ & 326.4 & 1.80 & 2.9 & 67.7 & 2.2 & 99.3 \\
\hline S25P950-1.5 & $131.1(2.6)$ & 317.2 & 1.75 & & 64.8 & & 102.3 \\
\hline L25P650-1.5 & $127.0(2.7)$ & 307.2 & 1.69 & 3.6 & 63.6 & 1.8 & 99.6 \\
\hline S25P650-1.5 & $122.6(2.8)$ & 296.6 & 1.63 & & 61.4 & & 99.7 \\
\hline L35P650-1.5 & $140.1(1.9)$ & 338.9 & 1.68 & 0.1 & 75.5 & 4 & 85.5 \\
\hline S35P650-1.5 & $139.9(1.4)$ & 338.4 & 1.68 & & 69.9 & & 100.2 \\
\hline L15P650-1.5 & $103.9(1.0)$ & 251.4 & 1.63 & 1.2 & 51.4 & 1 & 102.3 \\
\hline S15P650-1.5 & $102.7(1.3)$ & 248.5 & 1.61 & & 50.4 & & 103.9 \\
\hline L25P950-2.5 & $171.6(1.1)$ & 415.1 & 1.73 & 0.6 & 65.7 & 1.5 & 161.1 \\
\hline $\mathrm{S} 25 \mathrm{P} 950-2.5$ & $170.6(1.4)$ & 412.7 & 1.72 & & 63.2 & & 170.0 \\
\hline L50P650-2.5 & $200.4(1.7)$ & 484.8 & 1.51 & 6.4 & 76.4 & 4.4 & 162.2 \\
\hline S50P650-2.5 & $188.4(3.5)$ & 455.8 & 1.42 & & 68.1 & & 176.6 \\
\hline L15P550-2.5 & $141.8(1.1)$ & 343.0 & 1.57 & 1.9 & 44.0 & 0.4 & 222.1 \\
\hline S15P550-2.5 & $139.1(0.5)$ & 336.5 & 1.54 & & 43.5 & & 220.1 \\
\hline L35P550-2.5 & $178.9(3.4)$ & 432.8 & 1.58 & 3.8 & 72.6 & 2.4 & 146.3 \\
\hline S35P550-2.5 & $172.3(1.3)$ & 416.8 & 1.52 & & 68.4 & & 151.8 \\
\hline L25P500-2.5 & $159.0(1.6)$ & 384.7 & 1.60 & 5.2 & 62.1 & 1.3 & 155.9 \\
\hline S25P500-2.5 & $151.2(0.7)$ & 365.8 & 1.52 & & 60.1 & & 151.6 \\
\hline L25P650-2.0 & $142.6(0.8)$ & 345.0 & 1.71 & 0.5 & 62.1 & 1.4 & 129.6 \\
\hline $\mathrm{S} 25 \mathrm{P} 650-2.0$ & $141.9(1.2)$ & 343.3 & 1.70 & & 60.1 & & 136.0 \\
\hline L45P650-1.5 & $147.8(1.2)$ & 357.6 & 1.48 & 3.6 & 76.4 & 4.6 & 93.5 \\
\hline S45P650-1.5 & $142.6(1.3)$ & 345.0 & 1.43 & & 69.8 & & 104.4 \\
\hline L25P2000-1.0 & $117.0(0.8)$ & 283.0 & 2.01 & 7.5 & 60.2 & 1.7 & 94.2 \\
\hline S25P2000-1.0 & $108.8(1.6)$ & 263.2 & 1.87 & & 58.4 & & 86.2 \\
\hline L47P650-1.5 & $150.6(0.7)$ & 364.3 & 1.49 & 4.7 & 76.6 & 4.9 & 96.7 \\
\hline S47P650-1.5 & $143.9(3.8)$ & 348.1 & 1.42 & & 69.5 & & 107.1 \\
\hline L55P650-2.5 & $204.2(4.0)$ & 494.0 & 1.55 & 2.4 & 76.0 & 4.6 & 168.9 \\
\hline S55P650-2.5 & $199.4(1.1)$ & 482.4 & 1.51 & & 66.9 & & 198.1 \\
\hline
\end{tabular}

With respect to Table 4, the compressive strength of the LPSTC is only $0.1 \%-7.5 \%$ higher than that of the SPSTC demonstrating that maintaining the initial pressure in the LPSTC up to 6 days negligibly affects the compressive strength of the actively-confined concrete.

A significant part of the difference observed in the compressive strength between the two types of the confined concrete, i.e. LPSTC and SPSTC, comes from the difference in the compressive strength of their corre- sponding unconfined compressed concrete; hence, just a small part of it belongs to the difference in the prestressing value. To prove this, the compressive strength of the unconfined compressed concrete in the LPSTC and SPSTC specimens is obtained using the equations developed in the previous work (Nematzadeh, Naghipour 2012a), the results of which are given in Table 4. The contribution of the compressing concrete core to the relative increase in the actively-confined concrete strength is determined as the ratio of the compressive strength dif- 


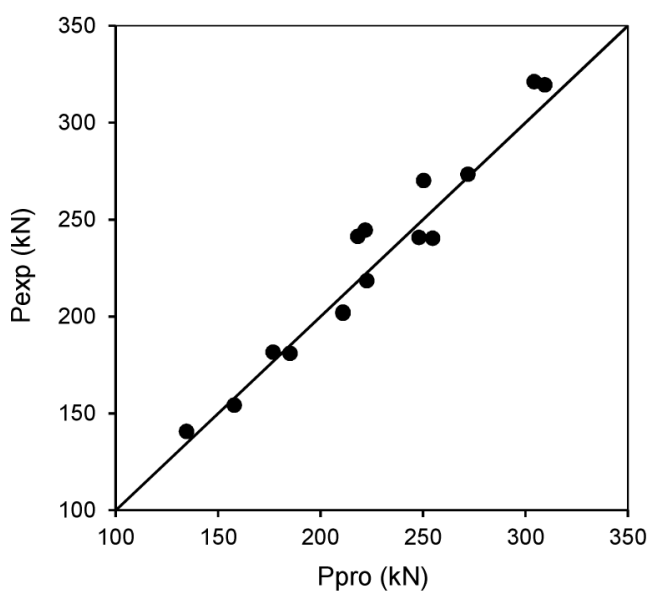

Fig. 5. Experimental and proposed load-carrying capacity of NPSTC specimens

ference between the LPCC and SPCC to the compressive strength of SPSTC $\left(=\left(f_{L P C C}-f_{S P C C}\right) / f_{S P S T C}\right)$. According to Table 4 , this ratio ranges from $0.4 \%$ to $4.9 \%$. The approximate contribution of prestressing to the relative increase of the actively-confined concrete strength can be calculated by subtracting the portion of compressed concrete core from the relative increase of the compressive strength, both of which were obtained previously. The portion of prestressing in the relative increase of the actively-confined concrete strength is obtained about $2 \%$ on average.

To develop the active confinement relationship, a comparison should be made between the compressive strength improvement of the actively-confined compressed concrete and that of the unconfined compressed concrete. The relative increase in the compressive strength of actively-confined concrete compared with that of the unconfined compressed concrete is presented in Table 4. The resulted values include both portions belonging to prestressing the steel tube and confining the concrete core; however, the contribution that compressing the concrete core has is not included.

Based on the test results, the value of $\alpha$ at the compressive strength of the actively-confined compressed concrete is obtained as about 0.5 . The circumferential stress and the confining pressure of the steel tube at the compressive strength of the PSTC can be determined by employing Eqns (6) and (7) with $\alpha=0.5$, thereby the corresponding confinement ratio is achieved as follows:

$$
\sigma_{\theta}=\frac{2 f_{y}}{\sqrt{7}} ; \quad f_{l}=\frac{4 t f_{y}}{\sqrt{7}(D-2 t)} ; \quad C_{r}=\frac{4 t f_{y}}{\sqrt{7}(D-2 t) f_{u c}},
$$

where $f_{u c}$ is the compressive strength of the unconfined compressed concrete. The prestressing ratio in activelyconfined concrete is defined in this paper as Eqn (13) in which $P_{f}$ (the final prestressing value) is assumed to be constant along the height of the STCC columns:

$$
P_{r}=\frac{P_{f}}{f_{u c}} .
$$

Table 5 provides the values of prestressing ratios. To determine the confinement strength of the activelyconfined concrete, only the circumferential stress of the steel tube which produces the lateral confining pressure should be considered (similar to section 2.2.1). The confinement strength of the LPSTC and SPSTC specimens and their relative increase compared with the compressive strength of the unconfined compressed concrete are presented in Table 5 .

The relationship between the relative increase in the confinement strength and both of the confinement ratio and the prestressing ratio is achieved for the LPSTC and SPSTC using the regression analysis of the experimental data as follows:

$$
\begin{aligned}
& \frac{f_{a c}-f_{u c}}{f_{u c}}=2.31\left(\frac{f_{l}}{f_{u c}}\right)^{0.7}\left(1+P_{r}\right) ; \quad R^{2}=0.91 \\
& \text { for LPSTC; } \\
& \frac{f_{a c}-f_{u c}}{f_{u c}}=2.31\left(\frac{f_{l}}{f_{u c}}\right)^{0.7}\left(1+2.9 P_{r}\right) ; \quad R^{2}=0.91 \\
& \text { for SPSTC, }
\end{aligned}
$$

where $f_{a c}$ is the confinement strength of actively-confined concrete.

In these two equations, the $P_{r}$ plays different roles, with the portion of $P_{r}$ in the relative increase of the confinement strength of the SPSTC being about 3 times greater than that of the LPSTC. The low effectiveness of prestressing the steel tube in the LPSTC than that of the SPSTC is due to the differences in preparing these two concrete types. Furthermore, the compressive strength of the unconfined compressed concrete in the PSTC specimens is measured after removing the confined concrete from the steel tube, which leads to emergence of microcracks in the concrete (Nematzadeh, Naghipour 2012a) as well as reduction of the compressive strength of the unconfined compressed concrete in the LPSTC due to its considerable final pressure. Therefore, the experimentally-measured compressive strength of the compressed concrete is lower than the actual value. This leads to a lower value of prestressing effectiveness coefficient in the LPSTC with respect to that of the SPSTC specimens. In this study, the prestressing effectiveness coefficient is defined as the ratio of the relative increase in the confinement strength resulting from the prestressing to the prestressing

ratio $\left(=\frac{\left(f_{a c}-f_{a c, P_{r}=0}\right) / f_{a c, P_{r}=0}}{P_{r}}\right)$, which is equal to 1.0 and 2.9 for the LPSTC and SPSTC, respectively.

The total load-carrying capacity of the actively-confined concrete can generally be determined by combining the strength of the composite components written as: 
Table 5. Confinement strength and load-carrying capacity results of actively-confined concrete

\begin{tabular}{|c|c|c|c|c|c|c|c|}
\hline $\begin{array}{l}\text { Specimen } \\
\text { identifier }\end{array}$ & $\begin{array}{l}\text { Confining } \\
\text { pressure } \\
(\mathrm{MPa})\end{array}$ & $\begin{array}{l}\text { Confinement } \\
\text { ratio }\end{array}$ & $\begin{array}{c}\text { Prestressing } \\
\text { ratio }\end{array}$ & $\begin{array}{l}\text { Confinement } \\
\text { strength } \\
(\mathrm{MPa})\end{array}$ & $\begin{array}{l}\text { Relative increase in } \\
\text { confinement strength } \\
\text { compared with compressed } \\
\text { concrete }(\%)\end{array}$ & $\begin{array}{l}\text { Proposed } \\
\text { load-carrying } \\
\text { capacity } \\
\text { (Ppro in } \mathrm{kN})\end{array}$ & $\begin{array}{l}\text { Ppro/ } \\
\text { Pexp }\end{array}$ \\
\hline L25P350-2.5 & 23.1 & 0.363 & 0.0695 & 142.7 & 124.7 & 398.9 & 0.99 \\
\hline $\mathrm{S} 25 \mathrm{P} 350-2.5$ & 23.1 & 0.376 & 0.0304 & 139.4 & 127.4 & 394.8 & 1 \\
\hline L25P950-1.5 & 13.8 & 0.204 & 0.1223 & 120.7 & 78.2 & 338.0 & 1.04 \\
\hline S25P950-1.5 & 13.8 & 0.213 & 0.0314 & 116.9 & 80.4 & 325.4 & 1.03 \\
\hline L25P650-1.5 & 13.8 & 0.218 & 0.0713 & 112.8 & 77.3 & 319.3 & 1.04 \\
\hline S25P650-1.5 & 13.8 & 0.225 & 0.0186 & 108.4 & 76.5 & 310.5 & 1.05 \\
\hline L35P650-1.5 & 13.8 & 0.183 & 0.0602 & 125.9 & 66.7 & 353.6 & 1.04 \\
\hline S35P650-1.5 & 13.8 & 0.198 & 0.0194 & 125.7 & 79.8 & 336.4 & 0.99 \\
\hline L15P650-1.5 & 13.8 & 0.269 & 0.0885 & 89.7 & 74.5 & 283.6 & 1.13 \\
\hline S15P650-1.5 & 13.8 & 0.274 & 0.0269 & 88.5 & 75.5 & 279.3 & 1.12 \\
\hline L25P950-2.5 & 23.1 & 0.351 & 0.1716 & 147.5 & 124.5 & 424.2 & 1.02 \\
\hline S25P950-2.5 & 23.1 & 0.365 & 0.0505 & 146.5 & 131.8 & 411.3 & 1 \\
\hline L50P650-2.5 & 23.1 & 0.302 & 0.0797 & 176.3 & 130.7 & 442.7 & 0.91 \\
\hline S50P650-2.5 & 23.1 & 0.339 & 0.032 & 164.3 & 141.2 & 418.2 & 0.92 \\
\hline L15P550-2.5 & 23.1 & 0.524 & 0.1151 & 117.7 & 167.4 & 339.4 & 0.99 \\
\hline S15P550-2.5 & 23.1 & 0.53 & 0.0475 & 115.0 & 164.3 & 341.1 & 1.01 \\
\hline L35P550-2.5 & 23.1 & 0.318 & 0.0698 & 154.8 & 113.2 & 428.6 & 0.99 \\
\hline S35P550-2.5 & 23.1 & 0.337 & 0.0302 & 148.2 & 116.6 & 418.2 & 1 \\
\hline L25P500-2.5 & 23.1 & 0.371 & 0.0819 & 134.9 & 117.2 & 396.4 & 1.03 \\
\hline S25P500-2.5 & 23.1 & 0.383 & 0.0203 & 127.1 & 111.4 & 385.8 & 1.05 \\
\hline L25P650-2.0 & 18.4 & 0.297 & 0.0819 & 123.5 & 98.8 & 357.2 & 1.04 \\
\hline S25P650-2.0 & 18.4 & 0.307 & 0.0203 & 122.8 & 104.3 & 347.4 & 1.01 \\
\hline L45P650-1.5 & 13.8 & 0.181 & 0.051 & 133.6 & 74.8 & 355.0 & 0.99 \\
\hline S45P650-1.5 & 13.8 & 0.198 & 0.0331 & 128.4 & 83.9 & 341.1 & 0.99 \\
\hline L25P2000-1.0 & 9.2 & 0.153 & 0.1456 & 107.6 & 78.7 & 272.1 & 0.96 \\
\hline S25P2000-1.0 & 9.2 & 0.158 & 0.0544 & 99.4 & 70.2 & 267.9 & 1.02 \\
\hline L47P650-1.5 & 13.8 & 0.181 & 0.0467 & 136.4 & 78.0 & 355.1 & 0.97 \\
\hline S47P650-1.5 & 13.8 & 0.199 & 0.0148 & 129.7 & 86.6 & 333.5 & 0.96 \\
\hline L55P650-2.5 & 23.1 & 0.303 & 0.0854 & 180.1 & 136.9 & 442.4 & 0.9 \\
\hline S55P650-2.5 & 23.1 & 0.345 & 0.0143 & 175.3 & 162.0 & 405.1 & 0.84 \\
\hline
\end{tabular}

$$
\begin{aligned}
& P_{a c}=A_{s} f_{y} \frac{\alpha}{\sqrt{1+\alpha+\alpha^{2}}}+ \\
& A_{c}\left[f_{u c}+k\left(1+k^{\prime} P_{r}\right) \frac{2 t f_{y}}{(D-2 t) \sqrt{1+\alpha+\alpha^{2}}}\right] \\
& \left\{\begin{array}{l}
P_{a c}=0.378 A_{s} f_{y}+\left[1+3.085\left(\frac{t f_{y}}{(D-2 t) f_{u c}}\right)^{0.7}\left(1+P_{r}\right)\right] A_{c} f_{u c} \text { for LPSTC; } \\
f_{u c}=-0.0331 f_{c}^{2}+3.185 f_{c} \quad \text { (in MPa) }
\end{array}\right. \\
& \left\{\begin{array}{l}
P_{a c}=0.378 A_{s} f_{y}+\left[1+3.085\left(\frac{t f_{y}}{(D-2 t) f_{u c}}\right)^{0.7}\left(1+2.9 P_{r}\right)\right] A_{c} f_{u c} \text { for SPSTC. } \\
f_{u c}=-0.0370 f_{c}^{2}+3.217 f_{c} \quad \text { (in MPa) }
\end{array}\right.
\end{aligned}
$$




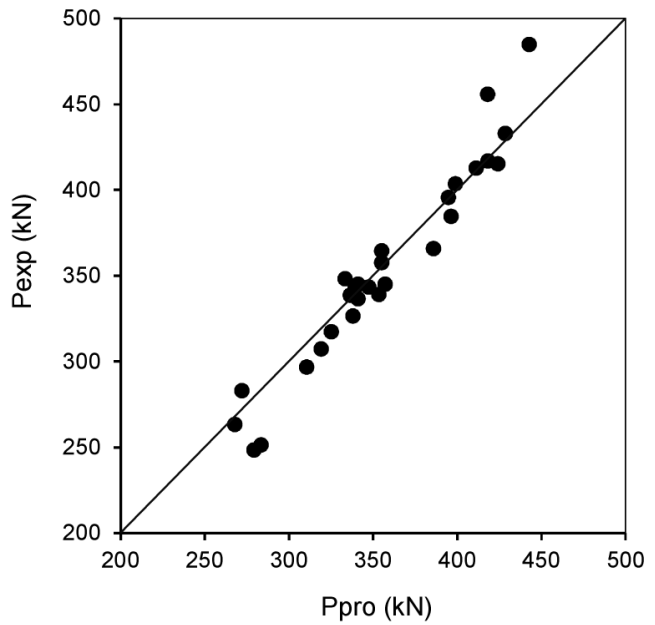

Fig. 6. Experimental and proposed load-carrying capacity of PSTC specimens

The load-carrying capacity obtained from the proposed models as well as its ratio to the experimental results is listed in Table 5 where it is observed that the average value of this ratio is 1.0. Moreover, the experimental and proposed load-carrying capacities of the PSTC specimens are depicted in Figure 6.

\subsection{Parametric study}

To conduct a parametric study, the compressive strength of the actively- and passively-confined concrete $\left(f_{c c}\right)$, defined as the ratio of the total load-carrying capacity of the confined concrete to the concrete cross-sectional area, can be calculated in terms of the three variable parameters in this study including $f_{c}, D / t$ and $P_{r}$ using the following equations. The range of these parameters is between 16.7 and $52.6 \mathrm{MPa}$ for $f_{c}, 24.2$ and 57.5 for $D / t$, and 0.01 and 0.17 for $P_{r}$ :

$$
\begin{aligned}
& f_{c c}=\frac{1.512(D / t-1) f_{y}}{(D / t-2)^{2}}+ \\
& {\left[1+3.085\left(\frac{f_{y}}{(D / t-2)\left(-0.0331 f_{c}^{2}+3.185 f_{c}\right)}\right)^{0.7}\left(1+P_{r}\right)\right]} \\
& \left(-0.0331 f_{c}^{2}+3.185 f_{c}\right)
\end{aligned}
$$$$
\text { for LPSTC; }
$$

$$
\begin{aligned}
& f_{c c}=\frac{1.512(D / t-1) f_{y}}{(D / t-2)^{2}}+ \\
& {\left[1+3.085\left(\frac{f_{y}}{(D / t-2)\left(-0.0370 f_{c}^{2}+3.217 f_{c}\right)}\right)^{0.7}\left(1+2.9 P_{r}\right)\right]} \\
& \left(-0.0370 f_{c}^{2}+3.217 f_{c}\right)
\end{aligned}
$$

for SPSTC;

$$
f_{c c}=\frac{2.32(D / t-1) f_{y}}{(D / t-2)^{2}}+\left(1+2.51 \frac{f_{y}}{(D / t-2) f_{c}}\right) f_{c}
$$

for NPSTC.

Based on Eqns (19)-(21), the relationships between the compressive strength and $D / t, f_{c}$, and $P_{r}$ for the actively- and passively-confined concrete are demonstrated in Figures 7-9. It can be seen from Figure 7 that with increasing $D / t$, the compressive strength of the LPSTC, SPSTC, and NPSTC decreases with a similar trend. Also, for all values of $D / t$, the compressive strength of the actively-confined concrete is significantly higher than that of the passively-confined one. Nevertheless, increasing the $P_{r}$ slightly raises the curve, and insignificantly improves the compressive strength of the confined concrete. Therefore, it can be found that applying a minimum level of prestressing $\left(P_{r}=0.01\right)$ is enough to achieve a high degree of strength improvement, thus further increasing it does not seem cost effective. It can also be seen from Figure 7 that the compressive strength of the SPSTC is very close to that of the LPSTC for lower values of $f_{c}$, while the difference between the two becomes more
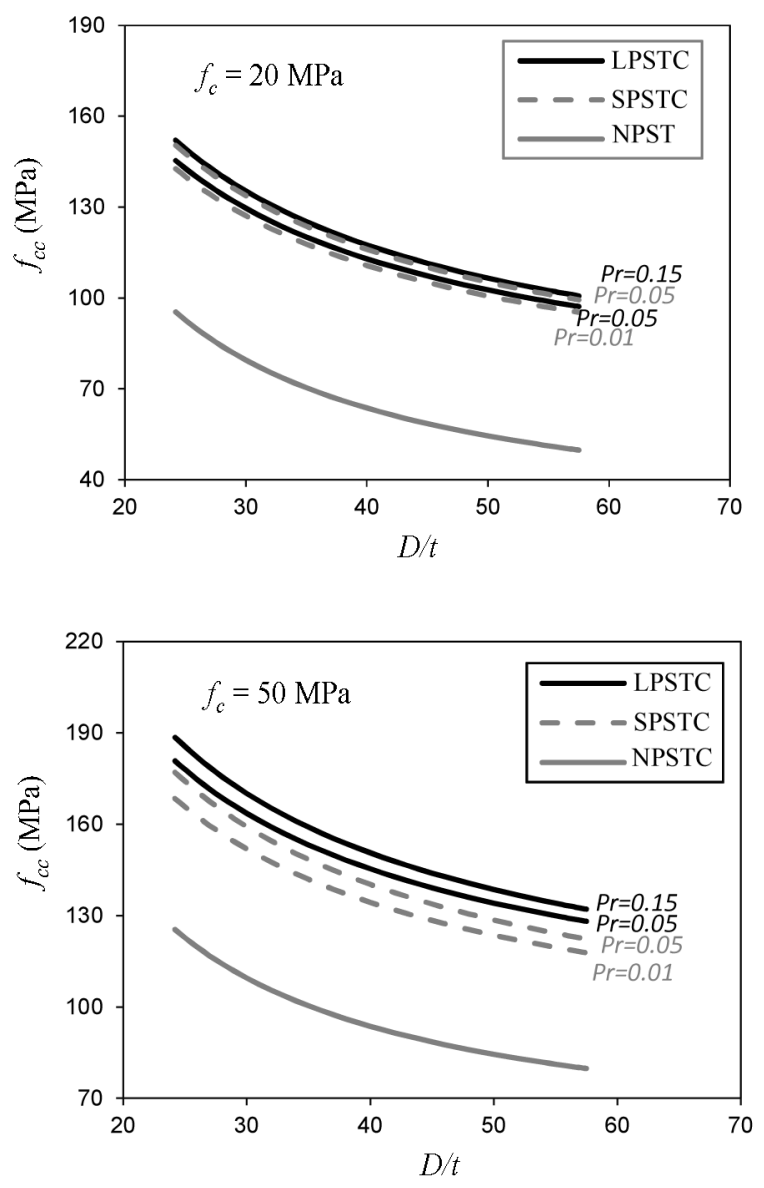

Fig. 7. Relationship of compressive strength of confined concrete $\left(f_{c c}\right)$ versus tube outer diameter to wall thickness ratio $(D / t)$ 

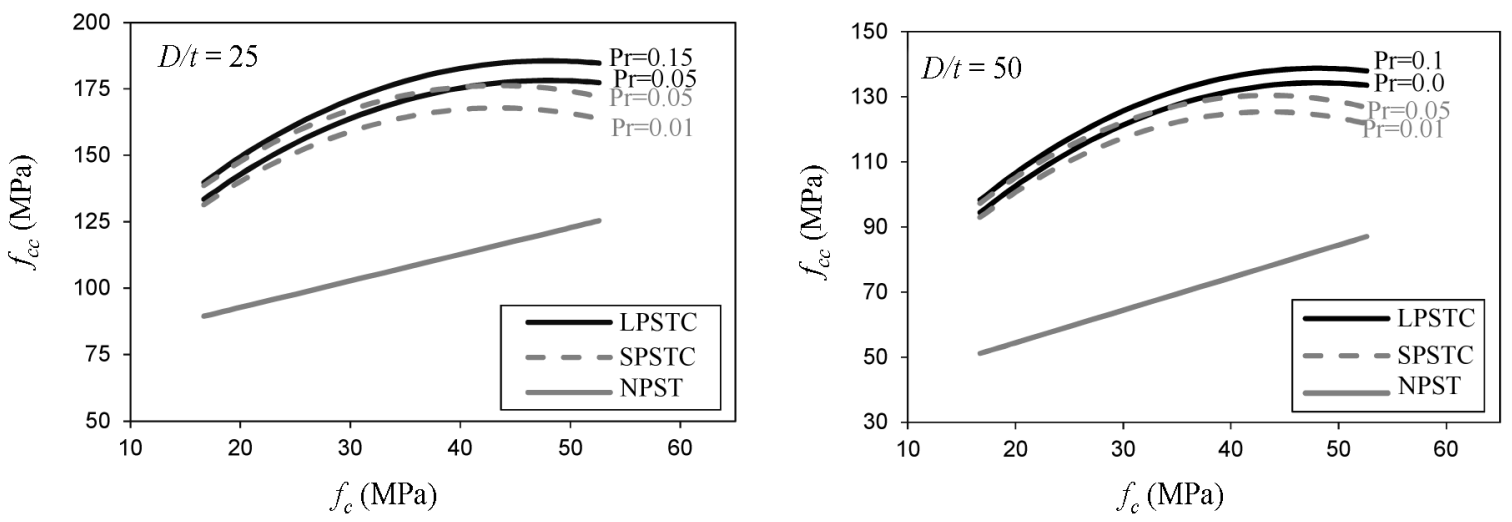

Fig. 8. Relationship of compressive strength of confined concrete $\left(f_{c c}\right)$ versus reference compressive strength $\left(f_{c}\right)$

significant for higher $f_{c}$, due to the considerable difference in their compressed concrete strength.

The relationship between $f_{c c}$ and $f_{c}$ is shown in Figure 8 in which it can be seen that with increasing $f_{c}$, $f_{c c}$ of the passively-confined concrete experiences a linear increase, which is in accordance with the Richart's equation. However, the compressive strength of the actively-confined concrete increases nonlinearly and with a sharper curve slope values for lower $f_{c}$, with the curve slope decreasing gradually with the increasing $f_{c}$.

The relationship between the compressive strength of the confined concrete and the prestressing ratio is illustrated in Figure 9.

In the first part of the curves, for the prestressing ratio ranging from 0.01 to 0.05 , the results of the SPSTC are employed, and in the second part of the curves, for the prestressing ratio ranging from 0.05 to 0.17 , the results of the LPSTC are utilized. Moreover, for the prestressing ratio of zero, the compressive strength of the NPSTC is applied in the curves. It can be seen from the figure that there is a significant improvement in the compressive strength for low levels of the prestressing ratio, while it is slightly affected by higher levels of the prestressing

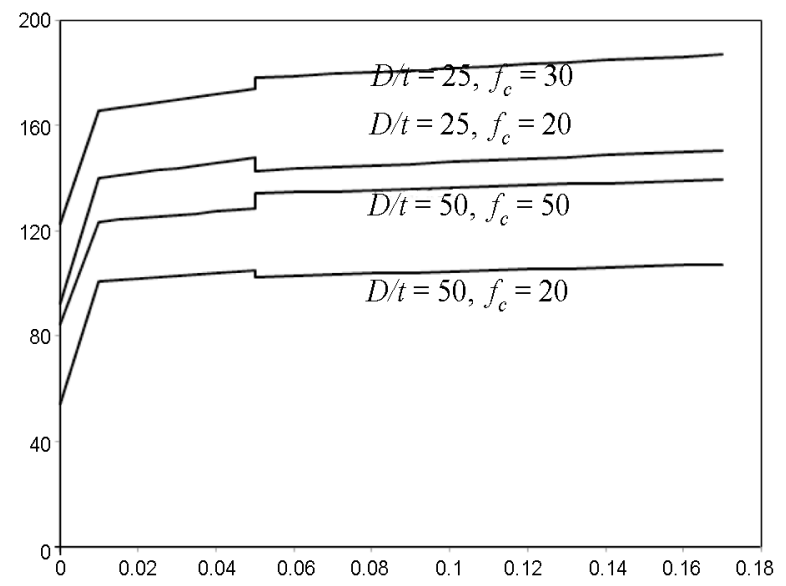

Fig. 9. Relationship of compressive strength of confined concrete $\left(f_{c c}\right)$ versus prestressing ratio $\left(P_{r}\right)$ ratio (greater than 0.01), as discussed earlier. Also, there is a spike in the curves at the connection point between the first and second part of the curves $\left(P_{r}=0.05\right)$, which is due to the fact that the LPSTC and SPSTC specimens exhibit different behaviors when subjected to prestressing. The spike of curves is upward for higher $f_{c}$, and for the lower values, it is the opposite.

\section{Conclusions}

Based on the experimental results of this study, the following conclusions may be drawn:

1. The confinement effectiveness coefficient value of the NPSTC in the proposed relationship is about half of that in Richart's model and is nearly 0.5 to 1 times that of the Mander's. Also, the confinement effectiveness coefficient of the actively-confined concrete is about 1.5 times greater than that of the passively-confined specimen.

2. Converting the confinement type to active by using the present technique can noticeably increase the load-carrying capacity of the confined concrete. The ratio of the compressive strength of the actively-confined concrete to that of the passively-confined one varies from 1.5 to 2 for the LPSTC and from 1.4 to 1.9 for the SPSTC.

3. While there is a substantial difference in the final pressure and the prestressing ratio between the LPSTC and SPSTC, the compressive strength of the LPSTC is only $0.1 \%$ to $7.5 \%$ higher than that of the SPSTC.

4. The contribution of prestressing to the relative increase in the compressive strength of the LPSTC compared with that of the SPSTC is obtained as about $2 \%$ on average. This indicates that applying long-term pressure to the confined concrete in order to reach a higher level of prestressing negligibly affects the compressive strength improvement, and hence a minimum level of prestressing $\left(P_{r}=0.01\right)$ is enough to achieve a high degree of strength improvement. 
5. The relative increase in the confinement strength of the actively-confined concrete in relation to the compressive strength of the corresponding unconfined compressed concrete tends to improve with the increase in both the confinement ratio and the prestressing ratio.

6. As the tube $D / t$ ratio increases, the compressive strength of the LPSTC, SPSTC, and NPSTC decreases with a similar trend.

7. With increasing $f_{c}$, the compressive strength of the passively-confined concrete increases linearly, while that of actively-confined concrete increases for lower values and decreases for higher ones. This suggests that improvement of the compressive strength of the actively-confined concrete prestressed using the present technique is more effective for lower reference concrete strengths.

\section{References}

ACI Committee 211.1-91:2000. Standard practice for selecting proportions for normal, heavyweight, and mass concrete. ACI manual of concrete practice, Part 1. Michigan, USA: American Concrete Institute.

ACI 318M-08:2008. ACI Committee 318. Building code requirements for structural concrete and commentary. Michigan, USA: American Concrete Institute.

AISC ANSI/AISC 360-05:2005. Specification for structural steel buildings. American Institute for Steel Construction, USA.

ASTM A370 Annual Book of ASTM Standard 01:2003. Standard test methods and definitions for mechanical testing of steel products. ASTM International.

AS3600:1994. Australia standards. Reinforced concrete structures. Sydney: Australia Standards.

ASTM C39/C39M Annual book of ASTM standard 04:2002. Standard test method for compressive strength of cylindrical concrete specimens. ASTM International.

CAN/CSA-S16-01:2001. Limit states design of steel structures. A National Standard of Canada.

CSA Standard, A23.3-04:2004. Design of concrete structures. Canadian Standards.

Chang, X.; Huang, C. K.; Chen, Y. J. 2009. Mechanical performance of eccentrically loaded prestressing concrete filled circular steel tube columns by means of expansive cement, Engineering Structures 31: 2588-2597. https://doi.org/10.1016/j.engstruct.2009.06.007

Dong, C. X.; Ho, J. C. M. 2015. Theoretical model for double-skinned concrete-filled-steel-tubular columns with external confinement, Journal of Civil Engineering and Management 21(5):666-76. https://doi.org/10.3846/13923730.2014.893913

Dundu, M. 2012. Compressive strength of circular concrete filled steel tube columns, Thin-Walled Structures 56: 62-70. https://doi.org/10.1016/j.tws.2012.03.008

EC4 BS EN 1994-1-1:2004. Design of composite steel and concrete structures - Part 1-1: General rules and rules for buildings. London, UK: British Standards Institution. Eurocode 4.

Feeser, L. J.; Chinn, J. 1962. Strength and stiffness of spirally prestressed concrete cylinders, ACI Journal Proceedings 7(3): 55-62.

Gardner, N. J.; Godse, R. M.; Wong, T. F. 1992. Laterally prestressed eccentrically loaded slender columns, ACI Structural Journal 89(5): 547-54.

Han, L. H.; Yao, G. H.; Chen, Z. B.; Yu, Q. 2005. Experimental behaviour of steel tube confined concrete (STCC) columns, Steel and Composite Structures 5(6):459-84. https://doi.org/10.12989/scs.2005.5.6.459

Han, L. H.; Qu, H.; Tao, Z.; Wang, Z. F. 2009. Experimental behaviour of thin-walled steel tube confined concrete column to RC beam joints under cyclic loading, Thin-Walled Structures 47(8-9): 847-857. https://doi.org/10.1016/j.tws.2009.03.001

Janke, L.; Zaderski, C.; Ruth, J.; Motavalli, M. 2009. Experiments on the residual load-bearing capacity of prestressed confined concrete columns, Engineering Structures 31: 2247-2256.

https://doi.org/10.1016/j.engstruct.2009.04.006

Krstulovic-Opara, N.; Thiedeman, PD. 2000. Active confinement of concrete members with self-stressing composites, ACI Materials Journal 97(3): 297-308.

Lee, H. P.; Awang, A. Z.; Omar, W. 2014. Steel strap confined high strength concrete under uniaxial cyclic compression, Construction and Building Materials 72: 48-55. https://doi.org/10.1016/j.conbuildmat.2014.08.007

Mander, B. J.; Priestley, J. N. M.; Park, R. 1988. Theoretical stress-strain model for confined concrete, Journal of Structural Engineering 144(8): 1804-1826. https://doi. org/10.1061/(ASCE)0733-9445(1988)114:8(1804)

Martin, C. W. 1968. Spirally prestressed concrete cylinders, ACI Journal Proceedings 65(10): 837-845.

Moghaddam, H.; Samadi, M.; Pilakoutas, K.; Mohebbi, S. 2010. Axial compressive behavior of concrete actively confined by metal strips; Part A: Experimental study, Materials and Structures 43(10): 1369-1381. https://doi.org/10.1617/s11527-010-9588-6

Mokari, J.; Moghadam, A. S. 2008. Experimental and theoretical study of reinforced concrete columns with poor confinement retrofitted by thermal post tension steel jacketing, Journal of Applied Sciences 8(24): 4579-4586.

Mortazavi, A. A.; Pilakoutas, K.; Son, K. S. 2003. RC column strengthening by lateral pre-tensioning of FRP, Construction and Building Materials 17: 491-497. https://doi.org/10.1016/S0950-0618(03)00046-1

Nemati, S. T. 2006. Effect of active confinement on concrete behaviour: Dissertation for Master's degree. University of Mazandaran (in Persian).

Nematzadeh, M. 2012. Determining the relationships of active confinement of fresh concrete by prestressing steel tubes: Dissertation for doctoral degree. University of Mazandaran (in Persian).

Nematzadeh, M.; Naghipour M. 2012a. Compressive strength and modulus of elasticity of freshly compressed concrete, Construction and Building Materials 34: 476-485. https://doi.org/10.1016/j.conbuildmat.2012.02.055

Nematzadeh, M.; Naghipour M. 2012b. Compressing fresh concrete technique and the effect of excess water content on physical-mechanical properties of compressed concrete, Materials and Design 37: 256-267. https://doi.org/10.1016/j.matdes.2011.12.051

Richart, F. E.; Brandtzaeg, A.; Brown, R. L. 1928. A study of the failure of concrete under combined compressive stresses. Bulletin 185, University of Illinois Engineering Experimental Station, Champaign 111.

Shinohara, Y. 2008. Effect of transverse prestressing on shear behaviors of high-strength concrete columns, in $14^{\text {th }}$ World Conference on Earthquake Engineering, 12-17 October 2008, Beijing, China.

Tomii, M.; Sakino, K.; Watanabe, K.; Xiao, Y. 1985. Lateral load capacity of reinforced concrete short columns confined by steel tube, in Proc. of International Specialty Conference on Concrete Filled Steel Tubular Structures, 1985, 19-26.

Tomii, M.; Sakino, K.; Xiao, Y. 1987. Ultimate moment of reinforced concrete short columns confined in steel tube, in 
Proc. of Pacific Conference on Earthquake Engineering, 5-8 August 1987, New Zealand, Vol. 2, 11-22.

Tran, H.; Balandraud, X.; Destrebecq, J. F. 2015. Improvement of the mechanical performances of concrete cylinders confined actively or passively by means of SMA wires, Archives of Civil and Mechanical Engineering 15(1): 292-299. https://doi.org/10.1016/j.acme.2014.04.009

Xiao, Y.; He, W. H.; Choi, K. K. 2005. Confined concretefilled tubular columns, Journal of Structural Engineering 131(3): 488-497. https://doi.org/10.1061/(ASCE)07339445(2005)131:3(488)

Yu, Q.; Tao, Z.; Liu, W.; Chen, Z. B. 2010. Analysis and calculations of steel tube confined concrete (STCC) stub columns, Journal of Constructional Steel Research 66(1): 53-64. https://doi.org/10.1016/j.jcsr.2009.08.003

Zhang, Y.; Zhao, J.; Yuan W. 2013. Study on compressive bearing capacity of concrete-filled square steel tube column reinforced by circular steel tube inside, Journal of Civil Engineering and Management 19(6): 787-795. https://doi.org/10.3846/13923730.2013.799088

\begin{tabular}{|c|c|}
\hline \multicolumn{2}{|c|}{ Nomenclature } \\
\hline CFST & Concrete Filled Steel Tube \\
\hline$L P C C$ & Long-term Pressure-Compressed Concrete \\
\hline LPSTC & $\begin{array}{l}\text { Long-term Prestressed Steel Tube-Confined } \\
\text { Compressed Concrete }\end{array}$ \\
\hline NPSTC & Non-Prestressed Steel Tube-Confined Concrete \\
\hline PSTC & $\begin{array}{l}\text { Prestressed Steel Tube-Confined Compressed } \\
\text { Concrete }\end{array}$ \\
\hline$S P C C$ & Short-term Pressure-Compressed Concrete \\
\hline SPSTC & $\begin{array}{l}\text { Short-term Prestressed Steel Tube-Confined } \\
\text { Compressed Concrete }\end{array}$ \\
\hline STCC & Steel Tube-Confined Concrete \\
\hline \multicolumn{2}{|c|}{ Notation } \\
\hline$A_{c}$ & Cross-section area of concrete \\
\hline$A_{s}$ & Cross-section area of steel tube \\
\hline$C_{r}$ & Confinement ratio \\
\hline
\end{tabular}

\begin{tabular}{|c|c|}
\hline$D$ & Outer diameter of steel tube \\
\hline$f_{a c}$ & $\begin{array}{l}\text { Confinement strength of actively-confined } \\
\text { concrete }\end{array}$ \\
\hline$f_{c}$ & Compressive strength of concrete \\
\hline$f_{c c}$ & Compressive strength of confined concrete \\
\hline$f_{l}$ & Lateral confining pressure \\
\hline$f_{l p c c}$ & Compressive strength of LPCC \\
\hline$f_{p c}$ & $\begin{array}{l}\text { Confinement strength of passively-confined } \\
\text { concrete }\end{array}$ \\
\hline$f_{s p c c}$ & Compressive strength of SPCC \\
\hline$f_{u c}$ & $\begin{array}{l}\text { Compressive strength of unconfined compressed } \\
\text { concrete }\end{array}$ \\
\hline$f_{y}$ & Yield strength of steel \\
\hline$k$ & Confinement effectiveness coefficient \\
\hline$k^{\prime}$ & Prestressing effectiveness coefficient \\
\hline$P_{a c}$ & Load-carrying capacity of PSTC \\
\hline$P_{f}$ & Final prestressing level \\
\hline$P_{i}$ & Initial prestressing level \\
\hline$P_{p c}$ & Load-carrying capacity of NPSTC \\
\hline$P_{r}$ & Prestressing ratio \\
\hline$t$ & Wall thickness of steel tube \\
\hline$\alpha$ & $\begin{array}{l}\text { Longitudinal to circumferential stress ratio of } \\
\text { steel tube }\end{array}$ \\
\hline$\sigma_{\theta}$ & Circumferential stress of steel tube \\
\hline
\end{tabular}

Mahdi NEMATZADEH. Assistant Professor at the Department of Civil Engineering, University of Mazandaran, Iran. Research interests: retrofitting and strengthening on steel and concrete structures, prestressed concrete, composite materials, experimental, modeling and analytical research on composite structures and sandwich panels.

Morteza NAGHIPOUR. Professor at the Faculty of Civil Engineering, Babol Noshirvani University of Technology, Iran. Research interests: offshore platforms (evaluation of behaviour), estimation of hydrodynamics forces on offshore structures, retrofitting and strengthening on steel structures, composite materials and their application on steel structures (and offshore structures), experimental, modelling and analytical research on steel and composite structural connections, shear walls and sandwich panels (evaluation of their seismic behaviour on duel systems).

Javad JALALI. Assistant at the Faculty of Civil Engineering, Babol Noshirvani University of Technology, Iran. Research interests: retrofitting and strengthening on concrete structures, prestressed concrete, composite materials.

Abolghasem SALARI. Master's graduate in Civil Engineering, Babol Noshirvani University of Technology, Iran. Research interests: experimental, modeling and analytical research on composite structures, prestressed concrete, composite materials. 